\title{
Abstract Photography as a Form of Art Education
}

\author{
Michele Astuto \\ Facoltà di Scienza dell’Educazione dell’Università di Granada, Michele Astuto via Vittorio Emanuele, 162 - 95042 - Grammichele \\ (CT), Italy
}

Received February 22, 2021; Revised June 3, 2021; Accepted June 20, 2021

\section{Cite This Paper in the following Citation Styles}

(a): [1] Michele Astuto , "Abstract Photography as a Form of Art Education," Universal Journal of Educational Research, Vol. 9, No. 8, pp. 1572 - 1580, 2021. DOI: 10.13189/ujer.2021.090809.

(b): Michele Astuto (2021). Abstract Photography as a Form of Art Education. Universal Journal of Educational Research, 9(8), 1572 - 1580. DOI: 10.13189/ujer.2021.090809.

Copyright $(2021$ by authors, all rights reserved. Authors agree that this article remains permanently open access under the terms of the Creative Commons Attribution License 4.0 International License

\begin{abstract}
This essay focuses on the comparative analysis between abstract and figurative photography and their possible combinations. Abstract photography is to be intended as an image in which the brain cannot recognize any shape or defined form, unlike figurative photography that portrays reality, or part of it, just as the eyes see it: this is the reason why abstract photography is almost a utopia, as the camera is a mechanic tool that captures subjects as they are. Abstract photography can be compared to the abstract painting of historical avant-garde movements in 10 th century art, where artists try to express sensations and feelings through colors, shapes and composition. The aim of the content analysis and its realization is to discover the critical thinking and its values, and the possible educational effects within the study context. This project aims to get a deeper look on the way abstract photography can influence the students of the Academy of Fine Arts "Michelangelo" during their studies. Furthermore, it tries to demonstrate whether the use of fantasy and colors can be a stimulating advantage in the photography process, as the freedom of artistic expression in the composition of abstract photography can facilitate one's personality expression, or, on the contrary, a disadvantage, considering the lack of rules of this subject, especially when compared to figurative photography. Theoretical reflection on the art itself and applied laboratory are fundamental to better understand the importance and the value of photography in the artistic, educative, communicative contexts. In fact, photography is an actual artistic instrument just as all the other arts, and as an expression and communication means, art can assume a significant role in the education field through the employment of images, laboratory activities and scientific practices and theories. The methodology followed for the aim of this study was based on a
\end{abstract}

quantitative approach, through the administration of a test to the sample of students, and a qualitative approach with a group discussion that followed the test, were art and abstract photography were the main topic. The test included multiple and open questions about art and photography related issues, while the group discussion was based on the observation and analysis of an abstract photography project. The participants were all students of the Academy of Fine Arts "Michelangelo" of Agrigento, only 16 were chosen based on their affinity and knowledge of art. The research showed the tendency and growing interest towards this photography genre and it was concluded with the students experimenting by themselves a new abstract photography through the off-camera process, which does not employ any camera or computer. To conclude, this work combines the analysis of the figurative narration with the possibilities of breaking the rules through abstraction, colors and creativity; in other words, this study deals with the importance of abstraction in the artistic field.

Keywords Education, Photography, Higher education, Visual culture, Visual Arts, Abstract Photography

\section{Introduction and Justification}

The field of photography has been a source of study and interest since its very origin (Guadagnini, 2000, p.3).The term photography (Guadagnini, 2000, p.3) derives from Greek: phôs (light) and gràphô (drawing, representation), reason why, starting from its etymological meaning, photography can be defined as the act of writing, drawing 
with the light. The meaning that it acquires is to be intended purely as the actual possibility for photography to provide a communicative and educational contribution in the field of art and abstract photography (Hargreaves, 1991, p.119).

Scholars, researchers and professors have a general agreement with what concerns the vital importance of children's education of artistic subjects: art can offer unique occasions for the development of personal skills, such as one's natural creative expression, social and moral values, as well as self-esteem development (Hargreaves, 1991, p. 126).

The language of photography has a strong communicative power and it plays an important role in the artistic field. As a matter of fact, with the advent of photography, modern art gets rid of all the rules that had been motive of constraint until then (Oliva, 2002). So, the image as a substitute of figurative art is mainly based on communication through a photography project, which aims to highlight not only the formal aesthetic characteristics, but also its complex narrative.

The purpose of this study is, therefore, showing and proving the contribution of abstract art for a brand new communicative and educational process (Paravia, 2007, p. 11) of "writing with the light" (Zannier, 2009, p. 291), and how the realization of an idea can become a work of art with an added value in the socio-cultural context.

The reason why this paper focuses more in depth on art photography (Zannier, 2009, p. 89) is due to the fact that often photography is not recognized as a possible alternative of painting, and in particular with the advent of digital technologies, it has turned to be considered into a simple image to be shared with friends on social networks (WhatsApp, Facebook, Instagram, etc.), more than a work of art able to make people feel better and/or a work that could be appreciated in museums, theatres or cinemas.

Within the education system, the relevance granted to the visual alphabetization in the first years is minimum compared to the other subjects. However, working with images in a classroom has a significant potential as a means of dialogue on three aspects. First of all, it is a means of photography techniques learning, during which style, aesthetic and visual artistic forms are developed. Also, it is a tool of communication and personal development, that encourages relationships between students. Finally, it is an important technique for personal and intellectual development, autonomy and critical thinking. For what concerns the importance of images since the very beginning of one's life, as Tisseron states:

"Images are very important since the very first months of life when the baby has a direct relation with images. The first relation occurs within the first weeks: when the infant is feeling hungry or cold, he cries and the mother responds; whenever this reaction has a delay, an important evolution occurs with regard to the role of images in his life".
The activity that has been realized for the sake of this research, with 16 students of the Academy of Fine Arts "Michelangelo" in Agrigento, was performed through the off-camera process.

The off-camera process consists in an analogical photographic procedure (Sorlin, 2001) that does not employ any computer or camera. Only the development of a new film roll, unexposed to light, is employed. The virgin roll is like a painting canvas board, which can actually be printed only later, in the preferred size, in the colors that will be converted in positive from negative (for example, blue will turn into yellow, red into cyan and so on) leaving the image just as it was created. In this way, the eye will be trained to a new vision of photography, namely abstract photography.

Through this educational process, students will understand the principle according to which abstract photography can be a reality, and that, depending on the refinement of the eye, it can turn into a real work of contemporary art, that can be used for video mapping projects, scenic projections, museum exhibitions, artistic and sensory rooms, etc.

The planning of an educational growth would be of fundamental importance (Baldacci, 2014) in order to form an artistic culture among children.

Eventually, it represents one of those issues that on an intellectual level, as well as for its educational interest and remarkable social impact, are perceived as more distinctive with respect to the other research areas of the didactics of the school curriculum (Dobbs, 1992; Efland, Freedman, Stuhr, 2003; Freedman, Hernàndez, 1998).

In this paper, photography is seen as an excellent means to encourage the artistic and media alphabetization, always from a visual perspective. Starting from here, the use of photo-dialogues will be taken into account, a work system defined by Roldán and Genet (2006) as such:

"A photo-dialogue is a dialogue made through photographs. Its fundamental purpose is teaching to develop a photographic visual thinking and, more in details, teaching photography through photographs. Photographs are the true core of the communicative sphere. In a photo-dialogue, every photograph is a question or an answer, an assent or a denial, a suggestion or a comment. The photographic sequences of a photo-dialogue provide concrete information about the meaning of a conversation, they are visual forms to be attended and understood, and from which one can also learn."

\section{Theoretical Framework}

Among the different reasons that lead to the work on a new film roll, unexposed to light, also called virgin, there is the tendency, more and more frequent, to associate art and photography. 
The photographic film can be a negative print film (Enrico Menduni, 2008) or a reversible one. The former turns the latent image in negative, then it is printed in the photographic paper in order to obtain the positive version, while with the reversible film, also known as slides, the development process turns the image in positive, with no projection or print.

In the field of photography, just as in all the Fine Arts, the term composition, as Fellini (2002, p.73) defines it, is: "the set of all the creative choices made by the photographer, or the artist, through which the image is composed".

In the case of a photograph, the choices include the different phases, starting from the reality standing in front of us, for example choosing the subject, and at the same time its shape in relation with the background and with the other elements of the image. In order to obtain a good result, the framing, the lens, the camera angle (and therefore the perspective) and other aspects determined essentially by the position of the photographer in the moment of the picture play a fundamental role as well.

The theory of composition, as Cassetti puts it, (1990) is: "the combination of all the decisions made by the photographer in the moment of taking a photo, as the subject choice and its relation with the surrounding environment."

Composition is fundamental in the photographic expression, being it just visual, without any voice-over or text describing the picture, every image will have a very personal interpretation given by the elements in it and their relations and their respective roles.

The "theory of composition" has the aim of showing rules or guidelines that allow the photographer to create harmonious or, more generally, expressive compositions. Many of them are pretty simple and show a clear influence of the rules of painting and figurative arts in general.

The probably most well-known rule is the so-called "rule of thirds". According to this rule, an imaginary grid formed by two vertical and two horizontal lines overlaps the image, which will be ideally divided into 9 equal parts. These frames serve as guidelines for the placement of the subjects: the central frame is marked by the intersection lines, also called focal points, and they represent the area where the eye tends to focus more and from which it gets information the most. In the case of off-camera photography, the rules of the composition are always applied to obtain harmonious and well calculated images.

As in any other form of art, photography does have rules, rules that in this very case will be broken. In fact, the film, the frame, the developing solution are very delicate elements and as a general rule, they have to be protected. But once aware of the rules, abstract photography breaks them, in order to obtain some other effect like with the volume or light. It is indeed very easy to damage a film and so obtaining different effects: just a scratch caused by the heat, chemical products or even a little cut with a nail are some of the ways that allow to control these kinds of aggressions and to create new and amazing images.

The most impressive distortions are produced by the heat, but also other different methods like the gluing of chemical substances applied to the virgin film roll, which can also be applied to a negative one already exposed to light and therefore, developed (figure 1).

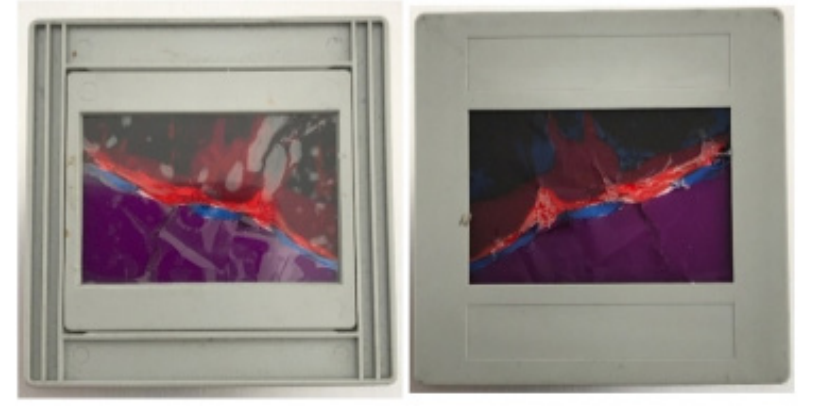

Figure 1. Michele Astuto (2015). Artistic Composition of a virgin roll film to be printed and projected in negative

The procedure is very complex and it is hard to obtain what one has in mind. In fact, once the processing of the picture is completed, it remains subject to changes and alterations for 24 hours, just as it was a rebellious soul trying to get out.

This type of photographs are called schadographie (Mario Costa, 2005, p.95), named after C. Schad, the first to experiment them, more commonly known as off-camera process.

Today's digital photography has brought many changes starting from Schad's idea, allowing the manipulation of images with the use of the computer, with the result that it is not possible anymore to talk of a photographic tool and that the final product cannot be seen as a probable artistic production.

Until the advent of digital technologies, photography has always been surrounded by a kind of aura of truth: it is commonly thought that, if an event is recorded photographically, therefore it is real, just as if the photography was some sort of automatic art.

In fact, in the era of its invention, painters loved to defame this new form of expression. But this is actually a false belief: whenever observing an event through the lens of a photograph, the event is not being seen directly, but what is perceived is always interpreted by the eye of the photographer and the technical tools that realized it. First of all, the photographer will choose what to show and what to hide: this is possible to observe when looking at different images of the same event realized in the same time span by two different photographers that offer two different versions, which are determined by their personal experiences and interpretations. A good picture is often a simple one, an image that can be interpreted clearly and directly, regardless the subject or reaction. More than on 
the use of powerful reflectors, motorized devices or long lenses, the success of a photograph depends on the ability of seeing it artistically, getting accustomed to that important imaginative effort that allows a trained eye to isolate a single detail, moving it away from a complex and confused world, in a constant movement.

\section{Objectives}

- Looking for a process, in the use of abstract photography, and implementation of an educational method in order to encourage the students to a critical attitude.

- Designing an educational activity with the purpose of visual alphabetization, through the use of images, assessing its efficacy and developing a critical and reflexive thinking in order to be able to produce a combination of different form of arts.

- Understanding whether the abstract photography is better than the figurative photography to stimulate the creative skills of the students.

- Verifying the realization of abstract photography through the off-camera process.

- Understanding if, through abstract photography and the artistic image, it is possible to better educate one's look to see beyond the thinking, perceive beyond the physical, beyond the 5 senses.

\section{Hypotheses}

The main hypothesis of this research concerns Art students, being them conscious of photography as a form of Art and of abstract photography as a real artistic form, at the same level of all the other forms of art and not as a minor one, as Giorgio Vasari wrote in 1550, dividing in the major arts (painting, carving, architecture) and the minor arte (majolica, joinery, etc.).

To understand whether abstract photography is better than figurative photography in stimulating the students' creativity, it is possible to rationalize (disassembling and assembling a figurative and an abstract work) the connections between figurative and abstract art.

The accomplishment of the formal dialogue is a fundamental step for knowledge in visual alphabetization, but understanding the process is the real artistic learning.

Besides this main hypothesis, here below are presented some partial hypotheses:

- 18+ years old students can handle technology to create digital images and, in turn, integrate consequently their pre-skills with art, learning the value of such.

- The creation and the direct use of the images should favor the conceptual assimilation of abstract and figurative photography contents. Creating images is the best way of learning, as the act of doing teaches more that the mere theory, in fact, the lab activity will be the tool through which they will assimilate the behind-the-scene work of an image. The materials will turn into a source of discovery for a use different than the original, a means for the visual expression and will become a new tool that the students will use in the process of their works of art.

\section{Methodology}

The planning of this research, both in its activities as in its sequence, was based on a participative approach in the process of teaching and learning.

This is why the activities are designed considering the student as the protagonist of own learning process, rather than a passive spectator. 16 students out of a total of 230 students enrolled in different study courses of the Academy of Fine Arts "Michelangelo" had to undergo a test with 20 questions, both open responses and multiple choices. They were chosen on the basis of another questionnaire, strictly related to art issues knowledge and their closeness with art.

The sample was so small just to give a first step and approach to such research and objectives.

The connection between new knowledge and foreknowledge has been a fundamental base for the achievement of a meaningful learning process.

Taking into account that 18 years old kids have already a well-established cultural background, the sensorial part of the right brain hemisphere was developed through practical exercises (Edwards, 2002), for a greater creativity.

At this point, the next step is the analysis of abstractionism in relation with cognitive and personality development theories.

This type of work has to be well planned and the development phases should be considered as the phases of personality development. Every work and every project is influenced and characterized by the state of mind of the artist in the moment of the creation. Every work of art reflects the exact moment of its realization, meaning that the colors, the sensations, the emotions may vary and be projected in the work, therefore change it.

"Emotions are a subjective reaction to different experiences associated with physiological and behavioral changes" as stated by Sroufe (1997, p. 57).

These emotions are part of the limbic system, which corresponds to the part of our brain that includes the hypothalamus, thalamus and amygdale that regulate, among others, the emotions. Emotions are needed as a communicative form, to express ourselves, verbally for example, as a protective form, as they help us in analyzing and solving problems, like the exploration of the environment or the learning of social norms. 
Having experience of our emotions and learning how to control them, in order to develop the emotional intelligence, can favor our personal development. Emotional intelligence enables to interpret, besides our owns, other people's emotions, developing empathy and comprehension.

Having control of the emotions allows to create images, photographs and Art, conveying personal state of mind in the context of our surroundings, reason why they acquire important relevance in the field of art.

\subsection{Methodological Framework}

The research was based on a content analysis, through a test administration with both open responses and multiple choices, including images, applying the quantitative methodology, and a group discussion, to obtain qualitative data. In this way, through the quantitative one, data about the use of variables with defined limits will be given (Sayago, 2014) while through the qualitative research, a wider perspective of the context taken into consideration will be obtained, where data are fundamental (Banks, 2008). According to Krippendorff, a content analysis is "the technique meant for formulating, starting from certain data, reproducible and effective implications that can be applied to a concept" $(1980$, p.28).

\subsection{Justification of the Sample}

This research is based on the results of a test and a class discussion administrated to 16 students from the Academy of Fine Arts of Agrigento. The test was carried out dividing the students into two groups according to their gender; this was done because women appear to be more sensible to art issues.

The majority of the students have shown to have a non-verbal visual learning style based on images, symbols, colors and a visual-spatial and iconic code. The approach of the students to the proposed activity was very positive, as they showed interest in the artistic methodology of abstract photography.
To summarize, the majority of the sample appears to be favorable to the novelty, meaning that they are willing to face new experiences, as abstract photography. That is why it is possible to know what kind of influences can be provided by abstract photography at the end of the studies.

\subsection{Tools Employed}

For the analysis of the different variables just mentioned, a test with open responses and multiple choices was employed: the test consists of different questions about content and theme, which can be considered as the variables of the research, being them content and theme. Content includes abstractionism sections, like characters, methodologies, space/scene, meaning that part of methodology to be used for the development of the work. On the other side, the theme section includes questions concerning the formal aspects, like colors, reading of the work, critique, so abstract photography as a means of visual communication, art education and integration.

The test includes 20 specific questions about photography and art in general. The questions strictly related to art knowledge will not be included in the following analysis as the aim was merely informative. The same group of students, besides the test, took part in a group discussion, with the professor having the role of moderator and listener, while the students debated about the different possibilities and contributions that abstract photography can provide to the visual communication and art education.

\section{Results}

This section shows the data obtained in the development of the research, which are presented in the graph. The following are the general data of the questionnaire done by the 16 students from the University of Fine Arts of Agrigento is presented. 


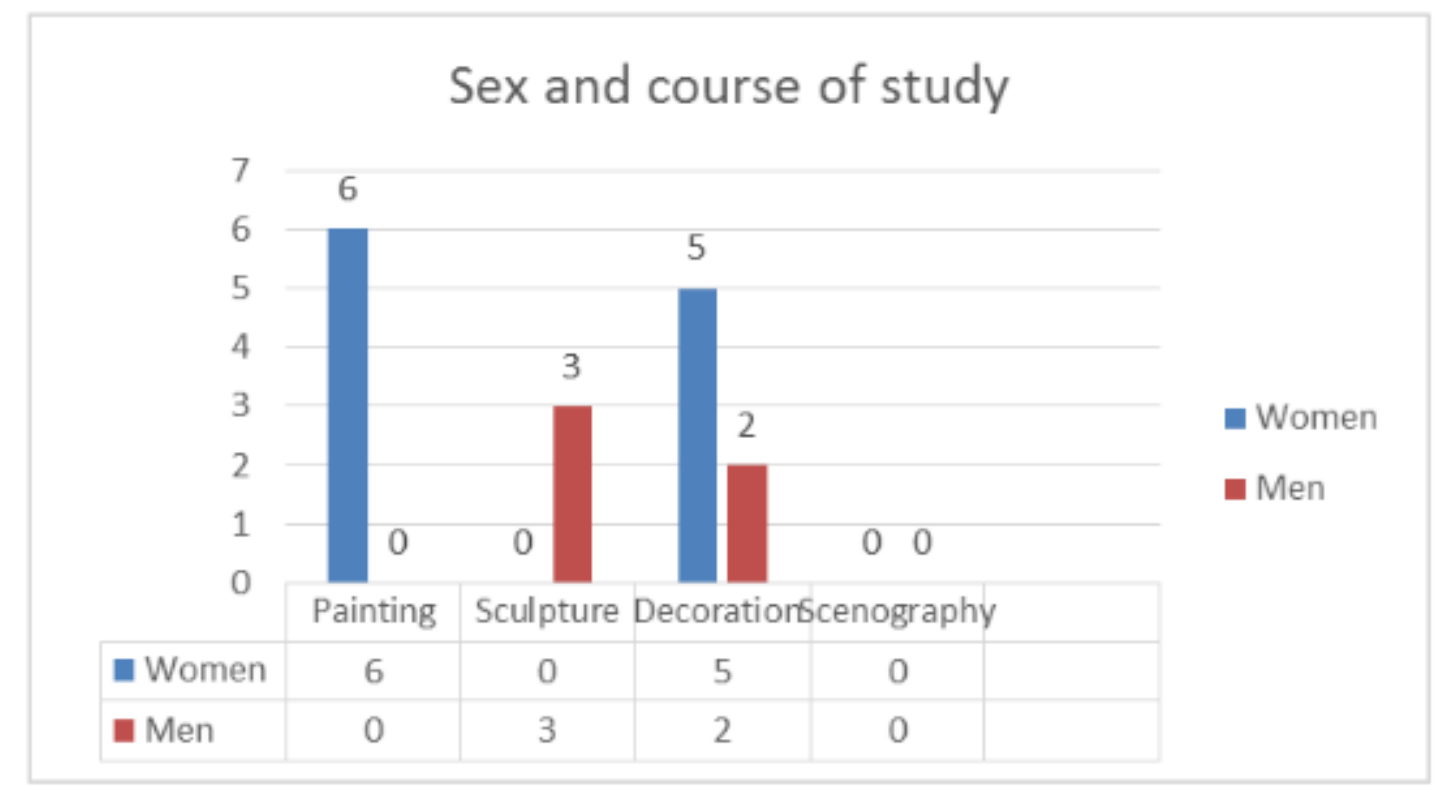

Women 68,75\% - Men 31,25\%

Women $=37,5 \%$ Painting $-31,25 \%$ Decoration

Men $=18,75$ Sculpture $-12,5 \%$ Decoration

Figure 2. Sex and course of study

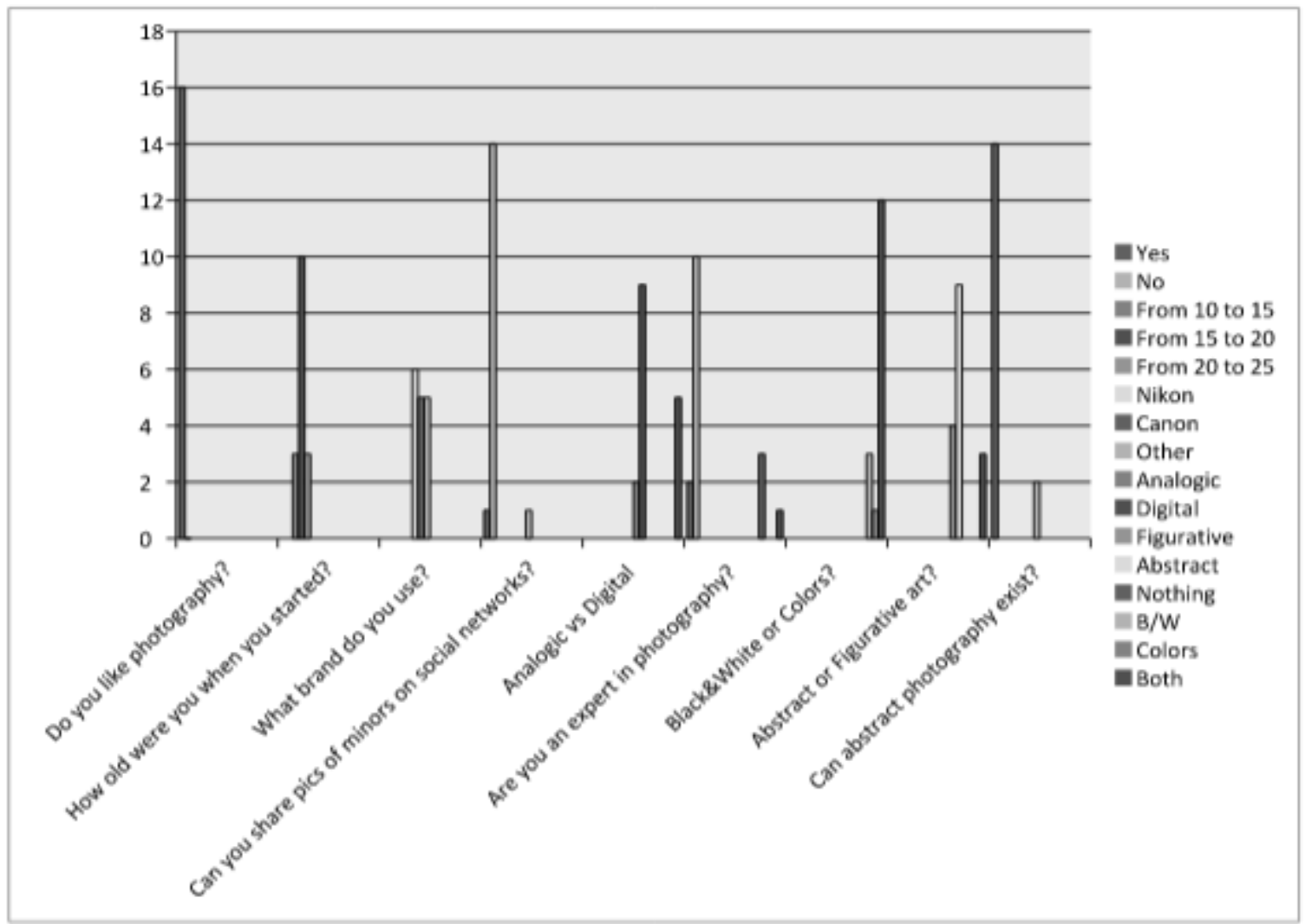

Figure 3. Questionnaire responses 


\subsection{Questionnaire Results}

In the above graphic (Figure 2), the students of the Academy were divided by gender and course of study. The sample of 16 students includes 11 women and 5 men, with 6 women studying painting and 5 studying decoration, while 3 men studying sculpture and 2 of them studying decoration; among the 16 students, no one was involved in the scenography studies. Moreover, the questionnaire shows the age of the interviewed, which are aged between 19 and 37 years old, of whom 8 already attended a photography course and 8 did not even choose photography as university subject.

The test that was administered to the students on June 25 th 2018 had some important outcomes that have been deducted:

- all of the 16 participants, both men and women, expressed their appreciation of photography

- $62,5 \%$ of them started taking photos between 15 and 20 years old, while $18,75 \%$ between 20 and 25 years old, and $18,75 \%$ in an early age between 10 an 15 years old.

- $68,75 \%$ of the students use well-known camera brands, for example: $37,5 \%$ uses Nikon and $31,25 \%$ uses Canon, while $31,25 \%$ thinks that they are on the same level and just $12,5 \%$ of them prefer the analogical.

- $87,5 \%$ of the interviewed knew well that it is not possible to share photos of minors on social networks without the consent of their parents, $6,25 \%$ thinks it is possible while $6,25 \%$ does not know.

- The majority of the students, $56,25 \%$, declares that digital photography is superior than the analogical.

- All of the 16 students are interested in photography, even if the questionnaire shows that not all of them practice it professionally or semiprofessionally. $62,5 \%$ of the students do not consider themselves as experts, only $12,5 \%$ does, knowing the technique and the history. This data appears to be particularly surprising in terms of abstract photography, given that, based on the questions about their knowledge, it was unknown to most of them and only $25 \%$ said to have some knowledge about it.

- To the question about their preference between black and white effect or colors, the majority expressed their preference for both, specifying that, depending on the subject, one effect is better than the other, while the rest of the respondents, $6,25 \%$ preferred colors and $18,75 \%$ black and white.

- Regarding art in general, so painting, sculpting, etc., $56,25 \%$ of the students prefer abstractionism, $25 \%$ figurative art and $18,75 \%$ does not have a clear preference.

- When questioned about the possibility of the existence of abstract photography, the group was divided: $12,50 \%$ had no idea about it and $87,50 \%$ of them were sure about its existence, but reckoned it as difficult in its realization, keeping into account the lack of competence in the sector.

\subsection{Interview Results}

After the test administration, it was considered appropriate to realize a group interview session, with the same group of students, in order to understand better their considerations about photography, abstractionism, figurative art and art in general. From this interview session, the data emerged have strengthened.

Abstract photography was the leitmotif of the research.

The group made some considerations about the possible realization and technique and everyone agreed on the use of the software for the realization and some particular techniques they did not know.

A new developed film was shown and they were asked to guess what it was. Many of them answered correctly and the youngest student, knowing that it was a film, did not know the reason why it was white, transparent, and asked the reason. So a new and developed film was shown, but this time it was decorated, colored, and so almost everyone could not tell what it was and what it was for. Eventually, after one hour of considerations, with a 50 inch screen, they were told that the projected image had been realized through the off-camera process.

Then, the group tried by themselves the realization of an abstract photograph in the analogical form, so without any help of software or computers in general.

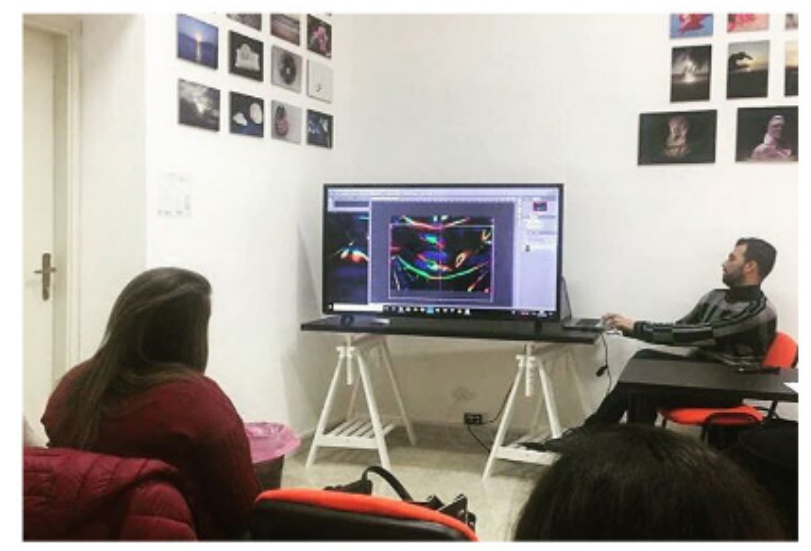

Figure 4. Classroom. Group discussion session about abstract photography (2018)

\section{Discussion and Conclusions}

This initial project allowed to understand that young students are more encouraged, stimulated and therefore incited to the study of art and photography. With abstract photography, it is possible to give free play to one\&\#39; imagination, even to those not really into the art studies and to the communication language through images. The 
laboratory integration through the off-camera process produced great results, as every student saw their critical thinking improve, through the realization of abstract photos, and this also favored a positive approach towards a critical reading of a work of art.

The planning of an integrated project involves a whole network, and this reality gets concrete as soon as the search for information about the project learning starts. When trying to find a definition, it gets clear that an exact one does not exist and that there is not a single agreement on the different phases, as the final organization of the project is the result of one's personal work. When realizing the planning of any project, it is important to consider the fact that the realized material should lead to real practice, to be adapted depending on the context or on the available resources.

One of the major difficulties that can be encountered planning a project is the choice of the main theme. Even realizing a survey to know the interests of the students, some uncertainty will remain about the selected theme, whether the group will be actually interested in it, for example, being this of vital importance to guarantee the success of the project itself. In fact, if all the students are interested, the motivation with be high, as well as their participation in the proposed activities. Since the very first moment of putting in practice a project, it should be kept into account that the planned activities could vary. So that whenever a new theme stimulates the students' interest, the activities will have to be adapted to satisfy their curiosity, always bearing in mind the main objectives. This essentially proves the fact that it is possible to learn through the art using any theme, for how little it may seem to be linked with it, as the human being learns above all in visual form.

Having the students realize a research about the knowledge they have to gain to carry out some task, makes the learning process meaningful and the assimilation more effective. In spite of this, a limited time is always considered, what provides inconveniences when carrying out the activities and when going into the investigation.

The goals achieved till now are a good start to address a better work planning on a regional scale, in different university institutions. However, in these first results it is clear that the students involved in the test are more motivated for abstractionism creations, as with the colors they can have free rein in the creative process. In the group interview, they have claimed that abstract photography realized through off-camera process can better combine any type of art and even overcome it, in some way, as it can be integrated with multimedia systems. Considering the sample of students, the journey undertaken was of education and alphabetization towards the abstract image, in order to become independent in the development of a critique and a constructive reflection about Arts.
When the students will approach to a project as professionals of the artistic field, it will make them consider the acquired knowledge very useful, as some of them might focus their studies on the photography universe, in order to enter the labor market as this or any other profession, in which the artistic and creative abilities have a major role.

Therefore, here a continuation of this research is proposed, not only on a theoretical level, as much information has been obtained from this study, but on a practical level, in a classroom full of students of different levels and institutions, with the aim of proving the actual efficacy and success of this methodology once the goals are achieved.

The sharing of this study is proposed as a methodological source for a wider use.

\section{REFERENCES}

[1] Arcari, A. (2007). Il lavoro educativo: 1\&\#39;importanza della relazione nel processo di insegnamento-apprendimento. Milano: Mondadori.

[2] Casetti, F.\&amp;Di Chio, F. (1990). Analisi del film. Milano: Bompiani.

[3] Costa, M. (2005). Dimenticare l'arte. Milano: Franco Angeli.

[4] Edwards, B. (2002). Il nuovo disegnare con la parte destra del cervello. Milano: Longanesi

[5] Ferrés y Prats, J. (2007). La competenciaencomunicación audiovisual: dimensiones e

[6] indicadores. Comunicar.

[7] Galesso, G. (2006). Parole per vedere. Lecce: Pensa Multimedia.

[8] Gardner, H. (1994). Educaciónartística y desarrollohumano. Barcelona: Paidós.

[9] Krippendorff, K. (1990). Metodología del análisis de contenido. Teoría y Práctica.Barcelona: Paidós.

[10] Menduni, E. (2008). La fotografia. Bologna: Il Mulino

[11] Millicent, M.(2002). After Fellini National Cinema in the Postmodern Age. USA: Johns Hopkins University Press

[12] Nieto Mesa, M. (2010). Guía para elaborar el marcometodológico. [PresentaciónenSlideshare]. Recuperado de http://bit.ly/1Rr4h6y.

[13] Piaget, J. (1972). Psicología y pedagogía. Barcelona: Ariel.

[14] Promenzio, L. (2010). Scrivere con la luceil design. La messa in scenadell\&\#39;oggettoattraversol\&\#39;immaginefotografi ca. Disponible desde: http://hdl.handle.net/10589/6464

[15] RichartBernabeu, R. (2007). Métodos y estrategiaseducativaspara la enseñanza de 
loselementosbásicosdelsistemadiédricoen enseñanzasecundaria. Departamento

FacultaddeBellasArtes, U.P.V.

[16] Silvestre, M. (1999). Aprendizaje, educación y desarrollo. Cuba: Pueblo y Educación.

[17] Sorlin, P. (2001). I figli di Nadar.Il secolo

de Dibujo. la

[18] Torres, M., Paz, K. \&amp; Salazar, F. (2006). Métodos de recolección de datos para unainvestigación. Rev. ElectrónicaIngenieríaBoletín. Madrid: Morata.

[19] Vygotsky, L. S. (1995). Pensamiento y lenguaje. A. Kozulin. Barcelona:Paidós. 